\title{
Abnormal semen parameters among males in infertile couples: a cross sectional study from a tertiary care centre
}

\author{
Jyoti Garg, Rachana Meena*, Shailaja Shukla, Sunita Sharma, Riva Choudhary
}

Department of Pathology, Lady Hardinge Medical College, New Delhi, India

Received: 09 June 2020

Accepted: 08 July 2020

\section{*Correspondence:}

Dr. Rachana Meena,

E-mail: rachanalhmc07@gmail.com

Copyright: (C) the author(s), publisher and licensee Medip Academy. This is an open-access article distributed under the terms of the Creative Commons Attribution Non-Commercial License, which permits unrestricted non-commercial use, distribution, and reproduction in any medium, provided the original work is properly cited.

\begin{abstract}
Background: In India, the prevalence of primary infertility ranges from $3.9 \%$ to $16.8 \%$. Male factor contributes 40 $50 \%$ of this. Male factor infertility is indicated by decreased sperm concentration, reduced motility, vitality or abnormal sperm morphology. Semen analysis is the single most important investigation to detect male factor infertility. The aim of this study was to analyse the prevalence of abnormal semen parameters among males in infertile couples and their association with contributing factors.

Methods: This cross-sectional hospital-based study was carried out in the Department of Pathology at Lady Hardinge Medical College and Smt. Sucheta Kriplani Hospital. A total of 400 cases were analyzed during a period of 6 months. Detailed history of the couple was taken. Semen analysis was done using automated semen analyzer (SQA-vision) after 3 days of abstinence according to the WHO $5^{\text {th }}$ edition 2010 guidelines. The results were analysed using excel sheet and SPSS software.

Results: In the present study, 122 cases (30.5\%) out of 400 cases had abnormal semen parameters. Most common abnormality detected was asthenozoospermia (14.3\%) followed by oligozoospermia (13.8\%), azoospermia (10.5\%) and teratozoospermia (10.5\%). There was significant association of alcohol intake, obesity and trauma with abnormal semen parameters.

Conclusions: Asthenozoospermia was the most common abnormality noted in this study. Lifestyle modifications along with timely medical attention in male partners of infertile couples can improve the semen quality.
\end{abstract}

Keywords: Alcohol, Asthenozoospermia, Male infertility, Semen analysis

\section{INTRODUCTION}

Infertility is a serious global issue which not only takes toll on couple's health but also has economic, demographic and social implications. It is increasingly becoming a constant cause of worriness in married couples. Globally, 8-12\% couples suffer from infertility. ${ }^{1,2}$

Infertility is defined as failure to achieve clinical pregnancy after 12 months or more of regular unprotected sexual intercourse. ${ }^{3}$ In India, the prevalence of primary infertility ranges from $3.9 \%$ to $16.82 \% .^{4}$ Male factor contributes $40-50 \%$ of this. ${ }^{5-7}$
Male factor infertility is indicated by decreased sperm concentration, reduced motility or abnormal sperm morphology in at least one sample of two semen analyses collected 1 and 4 weeks apart. ${ }^{8}$ Semen analysis is the single most basic and inexpensive test for evaluating and providing valuable information regarding male factor infertility. Timely assessment of semen parameters can lead to early identification of possible causes of infertility and institution of appropriate therapy if needed.

Objective of this study was to analyse the prevalence of abnormal semen parameters among males in infertile couples and their association with contributing factors. 


\section{METHODS}

A cross-sectional hospital-based study was carried out in the Department of Pathology at Lady Hardinge Medical College and Smt. Sucheta Kriplani Hospital. A total of 400 cases were analyzed during a period of 6 months. Detailed history of the couple was taken on a predesigned proforma for type of infertility (primary or secondary), age, education, occupation, tobacco chewing, smoking, alcohol, trauma and any surgical intervention. Physical examination was done. Height and weight were measured to get body mass index (BMI). Semen collection was done at the hospital in sterile container after 3 days of abstinence.

Informed verbal consent was taken from the individuals and confidentiality was ensured.

Sample was analysed for volume, $\mathrm{pH}$, pus cell count before further analysis by automated semen analyser (SQA-Vision) for sperm concentration, motility, vitality and morphology according to WHO 5th edition 2010 guidelines.

The lower reference limit according to WHO $5^{\text {th }}$ edition are as follows ${ }^{9}$ :

Volume - $1.5 \mathrm{ml}$, sperm concentration- 15 million spermatozoa $/ \mathrm{ml}$, total motility (progressive + nonprogressive motility) - $40 \%$, progressive motility $32 \%$, vitality - 58\%, sperm morphology - $4 \%$. Azoospermia is defined as absence of spermatozoa in sediment of centrifuged semen sample. Leucocytospermia is defined as pus cell count more than $1 \times 106 / \mathrm{ml}$.

\section{Statistical analysis}

The results were analysed using excel sheet and SPSS software. Data was presented in percentage. Univariate analysis was done using chi square test with $95 \%$ level of confidence limit. A p value less than 0.05 was taken to indicate a significant difference.

\section{RESULTS}

The mean age of the men in this study was 30.2 years with range of 19-48 years. Mean duration of marriage was 6.3 years. Majority of study population (74\%), came for consultation due to primary infertility. $50 \%$ of males had normal BMI. Only 7.8\% (31 cases) were illiterate and majority of population $(76.5 \%)$ was engaged in unskilled occupation.

History of alcohol intake, smoking and tobacco chewing was assessed according to criteria as defined by WHO. Among the study population of 400 cases, 51.5\% (206) gave history of alcohol consumption, 38\% (152) were smokers as well as tobacco chewers and 6\% (25) had positive history of exposure to dye/high temperature/paints.

Table 1: Characteristics of 122 cases with abnormal semen parameters.

\begin{tabular}{|c|c|c|}
\hline Characteristics & No. of cases & Percentage \\
\hline \multicolumn{3}{|l|}{ Age } \\
\hline$<30$ years & 76 & $62.3 \%$ \\
\hline$>30$ years & 46 & $37.7 \%$ \\
\hline \multicolumn{3}{|l|}{ BMI } \\
\hline Underweight & 14 & $11.5 \%$ \\
\hline Normal & 62 & $50.8 \%$ \\
\hline Overweight & 42 & $34.4 \%$ \\
\hline Obese & 4 & $3.3 \%$ \\
\hline \multicolumn{3}{|l|}{ Education } \\
\hline Illiterate & 11 & $9 \%$ \\
\hline Primary & 22 & $18 \%$ \\
\hline Middle & 18 & $14.8 \%$ \\
\hline High & 21 & $17.2 \%$ \\
\hline Intermediate & 19 & $15.6 \%$ \\
\hline Graduate & 26 & $21.3 \%$ \\
\hline professional & 5 & $4.1 \%$ \\
\hline \multicolumn{3}{|l|}{ Occupation } \\
\hline Unskilled & 80 & $65.6 \%$ \\
\hline Skilled & 40 & $32.8 \%$ \\
\hline Professional & 2 & $1.6 \%$ \\
\hline \multicolumn{3}{|c|}{ Duration of marriage (years) } \\
\hline$<5$ & 36 & $29.5 \%$ \\
\hline $5-10$ & 53 & $43.4 \%$ \\
\hline $10-15$ & 8 & $6.6 \%$ \\
\hline $15-20$ & 20 & $16.4 \%$ \\
\hline$>20$ & 5 & $4.1 \%$ \\
\hline \multicolumn{3}{|l|}{ Infertility } \\
\hline Primary & 93 & $76.3 \%$ \\
\hline secondary & 29 & $23.7 \%$ \\
\hline
\end{tabular}

Twenty cases $(5 \%)$ out of 400 cases had history of trauma, medical or surgical intervention. Out of 20 cases, 4 had history of trauma to inguinal region, 2 had history of genital tuberculosis, 4 had inguinal hernia, 1 had varicocele and 9 had hydrocoele.

Out of 400 cases, 122 cases $(30.5 \%)$ had abnormal semen parameters. Basic characteristics of cases with abnormal semen parameters are given below (Table 1).

\section{Semen analysis findings}

In the present study, 2\% (8) cases had oligospermia (semen volume $<1.5 \mathrm{ml}$ ). Leucocytospermia was present in 62 cases $(15.5 \%)$.

Out of 400 study population, $303(75.7 \%)$ cases had normal sperm concentration, 55 cases (13.8\%) had oligozoospermia and 42 cases $(10.5 \%)$ had azoospermia. 
Asthenozoospermia was seen in 57 cases (14.3\%) and teratozoospermia was detected in 42 cases $(10.5 \%)$.

Multiple semen parameter abnormalities were detected in 47 cases $(11.7 \%)$. Out of 47 cases, oligoasthenoteratozoospermia was detected in 27 cases $(6.7 \%)$, asthenoteratozoospermia in 13 cases $(3.2 \%)$, oligoasthenozoospermia in 5 cases $(1.2 \%)$ (Table 2$)$.

Table 2: Distribution of abnormal semen parameters (n-122).

\begin{tabular}{|lll|}
\hline $\begin{array}{l}\text { Abnormal Semen } \\
\text { parameters }\end{array}$ & $\begin{array}{l}\text { No. of } \\
\text { cases }\end{array}$ & \begin{tabular}{l} 
Percentage \\
\hline Azoospermia
\end{tabular} \\
\hline Oligozoospermia & 21 & $34.4 \%$ \\
\hline Asthenozoospermia & 12 & $17.2 \%$ \\
\hline Oligoasthenozoospermia & 5 & $4.8 \%$ \\
\hline Oligoteratozoospermia & 2 & $1.6 \%$ \\
\hline Asthenoteratozoospermia & 13 & $10.6 \%$ \\
\hline Oligoasthenoteratozoospermia & 27 & $22.1 \%$ \\
\hline
\end{tabular}

Association of abnormal semen parameters with contributing factors (addictions, demographic and others)

In the present study, asthenozoospermia showed statistically significant association with alcohol intake $(\mathrm{p}=0.014)$ and trauma/surgical intervention $(\mathrm{p}=0.050)$. Teratozoospermia also showed statistically significant association with alcohol consumption $(\mathrm{p}=0.003)$. Azoospermia was significantly associated with obesity $(\mathrm{p}=0.015)$.

Other factors like smoking, tobacco chewing, occupation, age, education etc showed no association with abnormal semen parameters.

\section{DISCUSSION}

Present hospital-based study was done to study semen parameters to detect male factor infertility and its association with any contributing factors.

\section{Semen analysis}

Asthenozoospermia was the most common (14.3\%) abnormality detected in the study population. Similar to this study result, Bodal et al, Ugboaja et al and Adenjiv et al reported asthenozoospermia with prevalence of $17 \%$, $16.7 \%$ and $27.8 \%$ respectively as most common semen abnormality in their studies. ${ }^{10-12}$

Oligozoospermia was seen in $13.8 \%$ cases which is similar to that reported by Kulkarni SN et al, Bodal et al and Bhaduri et al. ${ }^{10,13,14}$

Azoospermia was detected in $10.5 \%$ cases. Similar kind of results were seen in studies conducted by Josh et al,
Bhaduri et al and Agu et al who reported azoospermia in $11.0 \%, 12.42 \%$ and $14.2 \%$ of their study population respectively. ${ }^{14-16}$

Oligoasthenoteratozoospermia (OAT syndrome) was detected in $6.7 \%$ of cases in this study. Kulkarni et al, reported in $7.3 \%$ of cases, Butt and Akram et al in $9.09 \%$ and Agu et al in $11.6 \% .^{13,16,17}$

In the present study, overall prevalence of abnormal semen parameters was $30.5 \%$ which was similar to Raymont et al who reported abnormal semen parameters in $31.5 \%$ of their study population. ${ }^{18}$ Behrman et al reported abnormal semen parameters in $30-35 \%$ and Dor et al reported in $28 \%$ of their study population. ${ }^{19,20}$ However, studies conducted by Kulkarni et al and Bodal et al showed higher percentage of male factor infertility possibly due to small sample size and variation in geographic factors. ${ }^{10,13}$

Association of abnormal semen parameters with contributing factors (addictions, demographic and others)

Among the study population of 400 cases, $51.5 \%$ were alcoholics, $38 \%$ were smokers and tobacco chewers.

Alcohol has significant effect on semen parameters. It is said that long term consumption leads to reduction in hormonal levels thus hampering normal morphological development and maturation of spermatozoa. ${ }^{21}$ In this study, asthenozoospermia and teratozoospermia showed statistically significant association with alcohol consumption $(\mathrm{p}=0.014$ and $\mathrm{p}=0.003$ respectively). Similar result was obtained by Samal $\mathrm{S}$ et al, where alcohol addiction had statistically significant association with abnormal semen parameters $(\mathrm{p}<0.001) .^{22}$

Kalyani $\mathrm{R}$ et al, studied factors influencing quality of semen and found that reduction of sperm density was statistically significant in both alcoholics and tobacco users ( $\mathrm{p}$ value <0.05). ${ }^{23}$ However, in this study, smoking showed no association with abnormal semen parameters which could possibly be due to the lower number of smokers in the study population.

Because of sedentary lifestyle and improper diet, obesity is an increasing issue of concern. Increase in body fat has been associated with lower levels of total and free testosterone. Similar to this study result, Birander KD et al found significant association between abnormal sperm count and obesity $(\mathrm{p}=0.003){ }^{24}$

\section{CONCLUSION}

Male factor infertility is an important cause of infertility with significant psychological and social impact on the affected couples. In the present study, abnormal semen parameters were seen in a large proportion of the study population i.e., $30.5 \%$. Asthenozoospermia was the most common abnormality detected followed by 
oligozoospermia, azoospermia and teratozoospermia. Alcohol intake and obesity were found to significantly affect semen quality. Lifestyle modifications along with timely medical attention in male partners of infertile couples can address this issue.

\section{Funding: No funding sources}

Conflict of interest: None declared

Ethical approval: Not Required

\section{REFERENCES}

1. Sciarra J. Infertility: an international health problem. Int J Gynaecol Obstet. 1994;46:155-63.

2. Population Council. New Delhi: population council. infertility. Looking back, looking forward: a profile of sexual and reproductive health in India; 2004;6772.

3. Zegers-Hochschild F, Adamson GD, de Mouzon J, Ishihara O, Mansour R, Nygren K, et al. International committee for monitoring assisted reproductive technology (ICMART) and the world health organization (WHO) revised glossary of ART terminology. Fertil Steril. 2009;92:1520-4.

4. Calverton, Maryland, USA: ORC Macro and the World Health Organization. World Health Organization. Infecundity, Infertility, and Childlessness in Developing Countries. DHS Comparative Reports No 9; 2004.

5. Men's health - male factor infertility. University of Utah Health Sciences Center. Available at: http://web.archive.org/web/20080620064743/http://h ealthcare.utah.edu/healthinfo/adult/men/infertil.ht. Accessed on $11^{\text {th }} 2019$.

6. Brugh VM, Lipshultz LI. Male factor infertility: evaluation and management. Med Clin North Am. 2004;88(2):367-85.

7. Hirsh A. Male subfertility. BMJ. 2003;327(7416):669-72.

8. Biradar KD. Male factor in infertility: study from a tertiary care hospital. Int J Reprod Contracept Obstet Gynecol. 2016;5:2022-5.

9. World Health Organization.WHO laboratory manual for the Examination and processing of human semen. $5^{\text {th }}$ ed. Switzerland: World Health Organization; 2010: 1-102.

10. Bodal VK, Malik R, Kaur S, Bal MS, Kaur P, Bhagat $\mathrm{R}$, Singh KD, Goel A. Seminogram in male partners of infertile couples. Int $\mathbf{J}$ Med Dent Sci. 2014;3(1):276-84.

11. Ugboaja JO, Monago EN, Obiechina NJ. Pattern of semen fluid abnormalities in male partners of infertile couples in Southeastern, Nigeria, Niger J Med. 2010;19(3):286-8.
12. Adenijiv RA, Olayemi O, Okunlola MA, Aimakhu CO. Pattern of Semen analysis of male partners of infertile couples at the University College Hospital, Ibadan. West Afr J Med. 2003;22(3):243-5.

13. Kulkarni SN, Kulkarni NV. Study of semen parameters in male partners among infertile couples. Int J Reprod Contracept Obstet Gynecol. 2015;4:1016-9.

14. Bhaduri N, Sarkar AP, Dewasi N, Ghosh TK. Abnormalities in semen analysis among male partners of infertile couples: a study in a tertiary care level hospital of West Bengal, India. Int J Reprod Contracept Obstet Gynecol. 2015;4:100-2.

15. Joshi P, Gopal N, Bhat V. Study of semen analysis patterns in infertile males. Int $\mathrm{J}$ Pharm Bio Sci. 2011;1(1):44-9.

16. Agu O, Ibrahim SA, Muhammad Z. Determination of the semen quality in male partners of infertile couples in AMINU Kano teaching hospital, Kano. Ibom Med J. 2015;8(1):194-8.

17. Butt F, Akram N. Semen analysis parameters: Experiences and insight into male infertility at a tertiary care hospital in Punjab. J Pak Med Assoc. 2013;63(5):558-62.

18. Raymont A, Arronet GH, Arrata WSM. Review of 500 cases of infertility. Fertil Family. 1970;25(2):158-61.

19. Kistner RW. A rational approach to theevaluation of infertility. In: Behrman SJ and Kistner RW (eds). Progress of infertility. $2^{\text {nd }}$ ed. Boston: Little Brown; 1975:1-14.

20. Dor J, Homburg R, Rabau E. An evaluation of etiologic factors and therapy in 665 infertile couples. Fertil Steril. 1977;28(7):718-22.

21. Joo KJ1, Kwon YW, Myung SC, Kim TH. The effects of smoking and alcohol intake on sperm quality: light and transmission electron microscopy findings. J Int Med Res. 2012;40(6):2327-35.

22. Samal S, Dhadwe K, Gupta U. Epidemiological study of male infertility. Indian Med Gazette. 2012;5:174-80.

23. Kalyani R, Basavaraj PB, Kumar ML. Factors influencing quality of semen: a two-year prospective study. Indian J Pathol Microbiol. 2007;50(4):890-5.

24. Biradar KD. Male factor in infertility: study from a tertiary care hospital. Int J Reprod Contracept Obstet Gynecol. 2016;5:2022-5.

Cite this article as: Garg J, Meena R, Shukla S, Sharma S, Choudhary R. Abnormal semen parameters among males in infertile couples: a cross sectional study from a tertiary care centre. Int J Reprod Contracept Obstet Gynecol 2020;9:3398-401. 